\title{
BMJ Open Definition of whole person care in general practice in the English language literature: a systematic review
}

To cite: Thomas H, Mitchell G, Rich J, et al. Definition of whole person care in general practice in the English language literature: a systematic review. BMJ Open 2018:8:e023758. doi:10.1136/ bmjopen-2018-023758

- Prepublication history and additional material for this paper are available online. To view these files, please visit the journal online (http://dx.doi. org/10.1136/bmjopen-2018023758).

Received 25 April 2018 Revised 16 August 2018 Accepted 8 November 2018

Check for updates

(c) Author(s) (or their employer(s)) 2018. Re-use permitted under CC BY-NC. No commercial re-use. See rights and permissions. Published by BMJ.

${ }^{1}$ Primary Care Clinical Unit, Faculty of Medicine, University of Queensland, Herston, Queensland, Australia

${ }^{2}$ Psycho-Oncology Co-operative Research Group, Sydney Health Ethics, Faculty of Medicine, University of Sydney, Sydney, New South Wales, Australia

Correspondence to

Dr Hayley Thomas;

h.thomas@uq.edu.au

\section{ABSTRACT}

Objectives The importance of 'whole person' or 'holistic' care is widely recognised, particularly with an increasing prevalence of chronic multimorbidity internationally. This approach to care is a defining feature of general practice. However, its precise meaning remains ambiguous. We aimed to determine how the term 'whole person' care is understood by general practitioners (GPs), and whether it is synonymous with '[w]holistic' and 'biopsychosocial' care.

Design Systematic literature review.

Methods MEDLINE, PubMed, EMBASE, CINAHL, PsycINFO, Web of Science, Proquest Dissertations and Theses, Science.gov (Health and Medicine database), Google Scholar and included studies' reference lists were searched with an unlimited date range. Systematic or literature reviews, original research, theoretical articles or books/book chapters; specific to general practice; relevant to the research question; and published in English were included. Included literature was critically appraised, and data were extracted and analysed using thematic synthesis.

Results Fifty publications were included from 4297 nonduplicate records retrieved. Six themes were identified: a multidimensional, integrated approach; the importance of the therapeutic relationship; acknowledging doctors' humanity; recognising patients' individual personhood; viewing health as more than absence of disease; and employing a range of treatment modalities. Whole person, biopsychosocial and holistic terminology were often used interchangeably, but were not synonymous.

Conclusions Whole person, holistic and biopsychosocial terminology are primarily characterised by a multidimensional approach to care and incorporate additional elements described above. Whole person care probably represents the closest representation of the basis for general practice. Health systems aiming to provide whole person care need to address the challenge of integrating the care of other health professionals, and maintaining the patient-doctor relationship central to the themes identified. Further research is required to clarify the representativeness of the findings, and the relative importance GPs' assign to each theme.

PROSPERO registration number CRD42017058824.

\section{INTRODUCTION}

Societies worldwide are currently facing an increasing prevalence of patients with
Strengths and limitations of this study

To the best of our knowledge, this is the first systematic review of general practitioners' understandings of 'whole person', 'holistic' and 'biopsychosocial' care and the relationships between these terms.

- We used a comprehensive search strategy and included a broad range of literature types, to provide a sound understanding of these terms in English language general practice literature.

- This study was limited to English language literature, so does not provide insight into the use of these or related terms in other languages.

- Related terms such as 'patient-centred' care, 'generalism' and 'comprehensiveness' were not specifically studied, and additional work is required to determine their relationship to our findings.

- There was considerable heterogeneity in included publications, and it is possible that other researchers may identify different themes from the same data.

chronic multimorbidity. Provision of "whole person care' (WPG) is particularly important in meeting the needs of these patients and has been an objective of recent healthcare reforms in several nations. ${ }^{1-3}$

General practitioners (GPs) are particularly well placed to provide WPC. (The term general practice/general practitioner is used to incorporate both general and family practice throughout this report). A whole person or holistic approach characterises the self-definition of general practice, with its importance recognised by GPs from diverse cultural contexts and by patients. ${ }^{4-10}$ Historically, attention to WPC in western medicine developed in critique of the biomedical model's reductionist framework. ${ }^{11}{ }^{12}$ In 1977 , Engel proposed the 'biopsychosocial' model, a paradigm shift that recognised psychological and social along with biological contributors to disease. ${ }^{13}$ The terms 'holistic' and ‘whole person' care have been used to denote a similar approach. ${ }^{14-16}$

However, a series on the research agenda for general practice in Europe identified that 
despite the 'implicit consensus about [the importance of an holistic approach] as an essential element for GP, ${ }^{, 17}$ this lacked a clear practical definition, and little research had been conducted in the area. Indeed, 'many different definitions of holism, and holistic, are being used in health and the healthcare literature, and no one is quite sure what anyone else means when they use these terms' ${ }^{18}$ While the terms 'whole person', '[w] holistic' and 'biopsychosocial' care are sometimes used interchangeably, it is unclear whether they are synonymous, with differences between definitions proposed by general practice organisations. ${ }^{49}$ Additionally, it has been suggested that a commitment to WPC in general practice may be more rhetorical than practical. ${ }^{11} 19$ Given the core commitment of general practice to providing whole person, or holistic, care, as expressed in statements such as the World Organisation of Family Doctors' definition of general practice, this issue deserves attention. ${ }^{4}$ While studies have previously defined 'holistic care,' 'wholistic healthcare' and 'holistic practice', these have either focused primarily on the context of nursing or been conducted in a limited geographical location, and it is unclear whether their findings are transferrable to the general practice context. ${ }^{20-23}$ In order to evaluate the current concept of WPC within general practice and to design health system practices to provide WPC in a changing health climate effectively, it is first necessary to clarify how this term is defined. We conducted a systematic literature review and thematic analysis aiming to define how the term WPC is understood in general practice and whether it is synonymous with $[\mathrm{w}]$ holistic and biopsychosocial care.

\section{METHODS}

\section{Search strategy}

We searched the MEDLINE, PubMed, EMBASE, CINAHL, PsycINFO and Web of Science databases for published literature, and Proquest Dissertations and Theses, Science.gov (Health and Medicine database) and Google Scholar for grey literature, until April 2017. These databases were chosen to provide broad coverage of relevant subject areas. Results from Science.gov were limited to the 'top results' reported (maximum 500) and Google Scholar searches to the first 50 hits for each search string. We hand-searched the reference lists of included studies.

We developed search terms iteratively, then performed a preplanned search. The final strategy combined search terms for holistic, whole person or biopsychosocial with terms for general practice. The MEDLINE search strategy is shown in box 1 and was modified for other databases. Shorter search strings combining key search terms were used for Science.gov and Google Scholar due to functional limitations.

\section{Inclusion criteria}

Peer-reviewed systematic or literature reviews, original research (qualitative studies, quantitative studies with findings expressed as descriptive statements for inclusion

\section{Box 1 Medline search strategy}

((whole N5 person) OR whole-person OR (whole N5 patient) OR whole-patient OR wholistic OR wholism OR holism OR (holistic N5 medicine) OR (holistic N5 care) OR (holistic N5 view) OR (holistic N5 approach) OR (holistic N5 model) OR biopsychosocial OR bio-psycho-social OR bio-psychosocial OR biopsycho-social OR biopsychosociospiritual OR bio-psycho-socio-spiritual OR (MH holistic health) OR person-focused OR ("person focused")) AND (("general practi”") OR ("family doctor") OR ("family physician") OR ("family medicine") OR "generalist" $\mathrm{OR}(\mathrm{MH}$ general practice) $\mathrm{OR}$ (MH general practitioners) OR (MH family practice) OR ("primary care") OR ("primary health care") OR (MH primary health care) OR ("primary health*”) OR ("family practi*"))

MH, MeSH Heading; N5, near operator for within 5 words.

in qualitative analysis), theoretical articles or books/book chapters; literature specific to general practice (studies with a majority of GP or GP registrar participants or separate reporting of their views; text/opinion authored exclusively by GPs or GP registrars, or with at least one GP/GP registrar author and a focus on the general practice context); relevant to the research question (included descriptions, definitions or theoretical models of the terms 'whole person', 'holistic' or 'biopsychosocial' (care/medicine, etc)); and published in English.

\section{Exclusion criteria}

Non-English articles, articles not specific to general practice and literature authored by general practice professional organisations. The latter was excluded to achieve an understanding of WPC within academic general practice literature, which was likely to be the basis of general practice organisations' literature.

All eligible citations were uploaded into Endnote X8 and duplicates removed. Two independent reviewers (HT and JR) screened titles and abstracts. Studies that did not meet inclusion criteria were excluded, with disagreements resolved by discussion. A single reviewer (HT) assessed full text of remaining literature against inclusion criteria. Studies that this reviewer considered borderline or suitable for inclusion were reviewed by at least one other author (GM and/or MB), with disagreements resolved by discussion.

\section{Quality appraisal}

Qualitative studies' conduct and reporting were critically appraised using Kmet et $a l$ s Standard Quality Assessment Criteria. ${ }^{24}$ An additional question, 'Have ethical issues been taken into consideration?' was added, to give a total possible score of 22 . Validity and authenticity of book chapters and opinion pieces were appraised using Joanna Briggs Institute's Critical Appraisal Checklist for Text and Opinion. ${ }^{25}$ Initially, two reviewers (HT and MB) independently appraised five pieces of literature with disagreements resolved by discussion. Subsequent quality assessment was performed by a single reviewer (HT). No studies were excluded due to quality. 


\section{Data extraction}

Details including author, year, country, type of literature, population focus (for qualitative studies), key term (holistic, whole person, biopsychosocial) and descriptions of key terms were extracted by two reviewers (HT and $\mathrm{MB})$ for an initial five pieces of literature, and consensus was achieved. A single reviewer (HT) extracted data from remaining literature.

\section{Data analysis}

Full text of included studies was uploaded into NVivo 11. Original data relevant to the research question (including relevant results and original statements in discussion of qualitative studies, and original statements in books and theoretical pieces) were thematically coded. Two independent reviewers (HT and MB) performed coding inductively on an initial sample of five pieces of literature to search for concepts, with disagreements resolved by discussion. Following this, a single reviewer (HT) coded remaining literature. Subsequent studies were coded into pre-existing concepts, and new concepts were created when deemed necessary.

Thematic synthesis was performed by a single reviewer (HT) and discussed with another two reviewers (GM and MB) for consensus. ${ }^{26}$ Thematic synthesis was chosen as it allows development of interpretive theories while remaining close to the primary data. The terms 'whole person', 'holistic' and 'biopsychosocial' were then compared by exploring similarities and differences between the themes represented within each term, assisted by NVivo query functions. It was identified during analysis that variations of 'holistic' terminology (eg, holistic care, medicine, etc) may have different connotations, and these were subsequently compared. Temporal and geographical variations in usage were found to be absent.

\section{Patient and public involvement}

This research was done without patient involvement, due to its primary focus being on the understanding of WPC among GPs, and its nature as a systematic review.

\section{RESULTS}

Searches retrieved 4297 non-duplicate publications. Following title/abstract screen, 587 publications were selected for full text retrieval. We were unable to access eight of these despite conducting a library search. Of the remaining publications, 50 met inclusion criteria (figure 1). These originated from 12 countries, and comprised 5 qualitative studies, 40 theoretical articles, 4 book chapters and 1 thesis. The primary terms of interest were 'holistic' in 24 sources, 'whole person' in 9 sources, 'biopsychosocial' in 14 sources, both whole person/ holistic in 2 sources and both whole person/biopsychosocial in 1 source. None of the papers using whole person and only one paper using biopsychosocial terminology specifically aimed to define these terms, whereas multiple papers specifically defined holistic terminology. ${ }^{16} 1822$ 27-33 The characteristics of included literature and results of quality assessment are shown in online supplementary appendix 1 . We believe theoretical saturation was reached.

\section{Thematic synthesis}

There was substantial heterogeneity in the literature. However, six overarching themes were identified, each with between one and four subthemes. These are shown in table 1 and discussed below. Few sources specifically drew a distinction between whole person, holistic and biopsychosocial terminology, with several using these terms interchangeably. ${ }^{29} 31-38$ However, on overall analysis, we identified differences in emphasis, as discussed below and illustrated in figure 2. Subthemes that are relevant to more than one of the three terms overlap in the diagram.

\section{A multidimensional, integrated approach}

Employing a multidimensional, integrated approach, rather than a biomedical reductionist model, was the dominant theme throughout the literature.

The literature emphasised that biopsychosocial, holistic and whole-person approaches must address multiple aspects of the person and their context, rather than being strictly biomedical. ${ }^{16} 18222731333436$ 39-54 In a paper discussing the definition of holism, Freeman stated that:

An approach to health and medicine that is not reductionist is an implicit part of the comprehensive care provided by GPs. We are not doctors for particular diseases, or particular organs, or particular stages in the life cycle-we are doctors for people. ${ }^{18}$

Similarly, in a study on the perceived meaning of a (w) holistic view among GPs and district nurses in Sweden, Stranderg et al found that:

Biomedical attitude is not enough. There is a need for a multidimensional viewpoint including a bio-psychosocial attitude towards the patients. ${ }^{22}$

Which important aspects of the 'whole' to include in care varied. Biological, psychological and social factors were commonly identified. $^{12} 14161822272932333639-4345-47495153-56$ Some GPs argued for the importance of additional factors. Spirituality was prominent among these. ${ }^{1429} 333437394042444850545758$ Murray et al concluded from their study on GPs' views on their role in providing spiritual care that:

The whole-person approach to medicine may be incomplete if it lacks consideration of the spiritual dimension. ${ }^{37}$

The patient's ecological/environmental context was also emphasised by some GPs. ${ }^{14} 59$

The literature also emphasised that aspects of the person must be viewed in an integrated fashion. ${ }^{161827-29} 31-3336394042-47525355565860$ In their study 


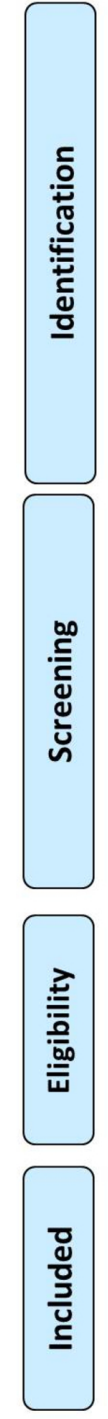

Records identified through

database searching

$(n=7454)$

Includes: MEDLINE ( $n=1793)$;

PubMed ( $n=624)$; CINAHL $(n=636)$;

EMBASE $(n=1627) ;$ PsycINFO

$(n=1009)$; Web of Science $(n=1283)$;

Proquest Dissertations and Theses

( $n=170)$; Science.gov $(n=312)$
Additional records identified through other sources $(n=77)$
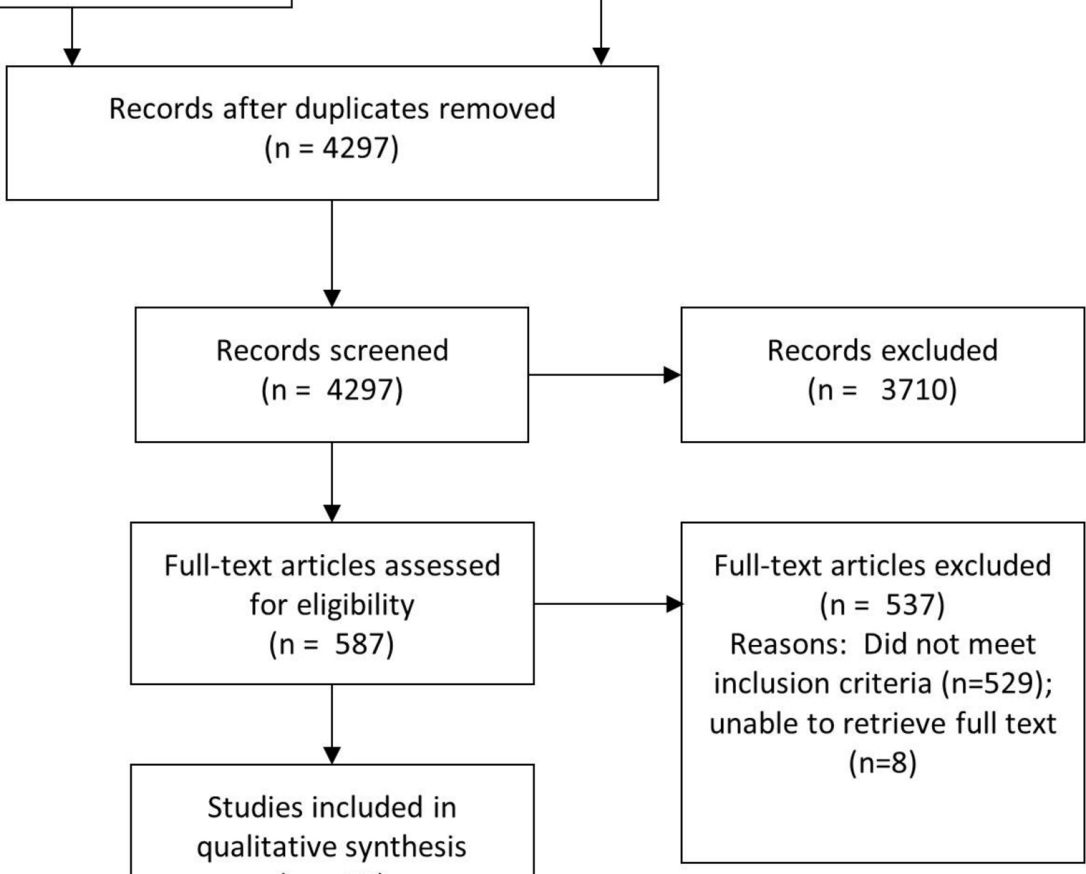

$(n=50)$

Figure 1 Preferred Reporting Items for Systematic Reviews and Meta-Analyses diagram.

on the meaning of an (w)holistic view, Strandberg et al found that:

The participants discussed the concepts 'the whole' versus 'parts of the whole'. Many meant that the whole actually is greater than the sum of all the parts... ${ }^{22}$

Similarly, Pietroni stated that a key principle of holistic medicine is that:

The human organism is a multidimensional being, possessing body, mind and spirit, all inextricably connected, each part affecting the and whole and the whole being greater than the sum of the parts. ${ }^{29}$

Sturmberg identified 'understanding the interconnectedness of various illness aspects ${ }^{53}$ as the second step in an approach to teaching holistic care.

One exception to this emphasis on a multidimensional, integrated approach was identified in O'Brien $e t$ $a l$ s study. ${ }^{38}$ GPs in one practice in this study understood holism as caring for a patient's multiple comorbidities and placed boundaries between 'the medical' and 'the social'.
Some authors also proposed a 'split biopsychosocial model' in which different components of care are selectively addressed depending on the patient's presentation, though the utility of this approach was debated. ${ }^{4360-62}$

Employing a multidimensional, integrated approach to care was the key theme characterising each of the biopsychosocial, holistic and whole person terminologies. ${ }^{16} 1822272931-3436$ 39-56

Biopsychosocial terminology was the most specific of the terms in defining the aspects of care that it addressed (biological, psychological, social). ${ }^{36} 414346$ Some GPs suggested the biopsychosocial approach was too narrow and should be expanded to a 'biopsychosociospiritual' ${ }^{34}{ }^{39}$ “ecobiopsychosocial ${ }^{, 59}$ or 'psychosomatosociosemiotic' model..$^{5363}$ Occasionally, the term biopsychosocial was used to incorporate these broader aspects. ${ }^{33}$ There was some debate regarding whether the biopsychosocial model employed an integrated approach, with some arguing that it remained dualistic. ${ }^{45564}$

Whole person and holistic terminology were less specific than biopsychosocial in defining their domains 


\begin{tabular}{|c|c|c|}
\hline Theme & Subthemes & $\begin{array}{l}\text { Terms characterised by this } \\
\text { theme }\end{array}$ \\
\hline $\begin{array}{l}\text { Employs a } \\
\text { multidimensional, } \\
\text { integrated approach }\end{array}$ & $\begin{array}{l}\text { Considers multiple aspects of the person and their context. } \\
\text { Integrates these aspects such that the whole is seen as greater } \\
\text { than the sum of the parts. }\end{array}$ & $\begin{array}{l}\text { Biopsychosocial } \\
\text { (multidimensional } \pm \text { integrated) } \\
\text { Whole person } \\
\text { Holistic }\end{array}$ \\
\hline $\begin{array}{l}\text { Importance of } \\
\text { the therapeutic } \\
\text { relationship }\end{array}$ & $\begin{array}{l}\text { Values the therapeutic relationship. } \\
\text { Places importance on personal attributes of the doctor that foster } \\
\text { the therapeutic relationship. } \\
\text { Employs a collaborative approach that emphasises patient } \\
\text { responsibility. } \\
\text { Values continuity of care. }\end{array}$ & $\begin{array}{l}\text { Biopsychosocial (variable) } \\
\text { Whole person } \\
\text { Holistic }\end{array}$ \\
\hline $\begin{array}{l}\text { Acknowledges the } \\
\text { humanity of the } \\
\text { doctor }\end{array}$ & $\begin{array}{l}\text { Places importance on doctors' self-awareness. } \\
\text { Adopts a 'physician heal thyself' philosophy. } \\
\text { Identifies potential for personal growth of the doctor through } \\
\text { treating the patient. }\end{array}$ & $\begin{array}{l}\text { Biopsychosocial (self-awareness) } \\
\text { Whole person } \\
\text { Holistic }\end{array}$ \\
\hline $\begin{array}{l}\text { Health as more than } \\
\text { absence of disease }\end{array}$ & $\begin{array}{l}\text { Health is viewed as more than the absence of disease. } \\
\text { Disease is viewed as a state of imbalance and healing as } \\
\text { restoring the balance of health. } \\
\text { Emphasises preventive health measures. }\end{array}$ & $\begin{array}{l}\text { Biopsychosocial (minor theme) } \\
\text { Whole person (minor theme) } \\
\text { Holistic }\end{array}$ \\
\hline $\begin{array}{l}\text { Employs a range of } \\
\text { treatment modalities }\end{array}$ & $\begin{array}{l}\text { Use of a range of treatment modalities. } \\
\text { May include (but is not synonymous with) CAM. }\end{array}$ & $\begin{array}{l}\text { Biopsychosocial } \\
\text { Whole person } \\
\text { Holistic (specific focus on CAM) }\end{array}$ \\
\hline
\end{tabular}

CAM, complementary and alternative medicine.

of care, encompassing a varied and broad range of biological, psychological, social, spiritual and environmental/ecological aspects. ${ }^{16} 1827343940424447485154$ Some models of WPC specifically distinguished between care of the person (body, soul, spirit) and external factors (social, environmental). ${ }^{39} 47$ However, these still addressed external factors in their overall approach to care. Emphasis on an integrated approach was strongest in holistic terminology, and also present in whole person terminology. ${ }^{161827-293132394044455253555658}$

Importance of the therapeutic relationship

The importance of the therapeutic relationship, a collaborative approach and characteristics of the doctor that fostered this relationship was emphasised. ${ }^{12} 14162227-3032333538394243454648505254555765-69$

The therapeutic doctor-patient relationship was valued. ${ }^{1282950}$ Risdon and Edey stated that:

True healing and mending of brokenness is possible only within an authentic human relationship. ${ }^{50}$

Similarly, McWhinney argued that:

There is a growing body of scientific evidence that human relationships are an important factor in the favorable outcome of illness. Thus we have support for the ancient belief in the healing power of the physician. ${ }^{28}$

O'Brien et al included relationship as a suggested component in a whole person intervention. ${ }^{38}$ One GP in their study:

describ[ed] how she felt the essence of the GP (relationship, intuition, support and continuity) had been lost with the medical nuts \& bolts of monitoring..., a view supported by her colleagues.

Personal qualities of the doctor that fostered the therapeutic relationship were emphasised. 182729323839465255576061656769 These included characteristics such as being fully present, attentive to and interested in the patient, supportive (compassionate, empathetic, respectful, non-judgemental, etc) and possessing knowledge and understanding of the patient in addition to technical competence. Participants in Strandberg $e t a l$ s study identified that an important component of a holistic view was:

finding the patient's hidden agenda and listening to what the patient is actually saying. ${ }^{22}$

Multiple sources emphasised a collaborative approach, with patients taking responsibility for their 


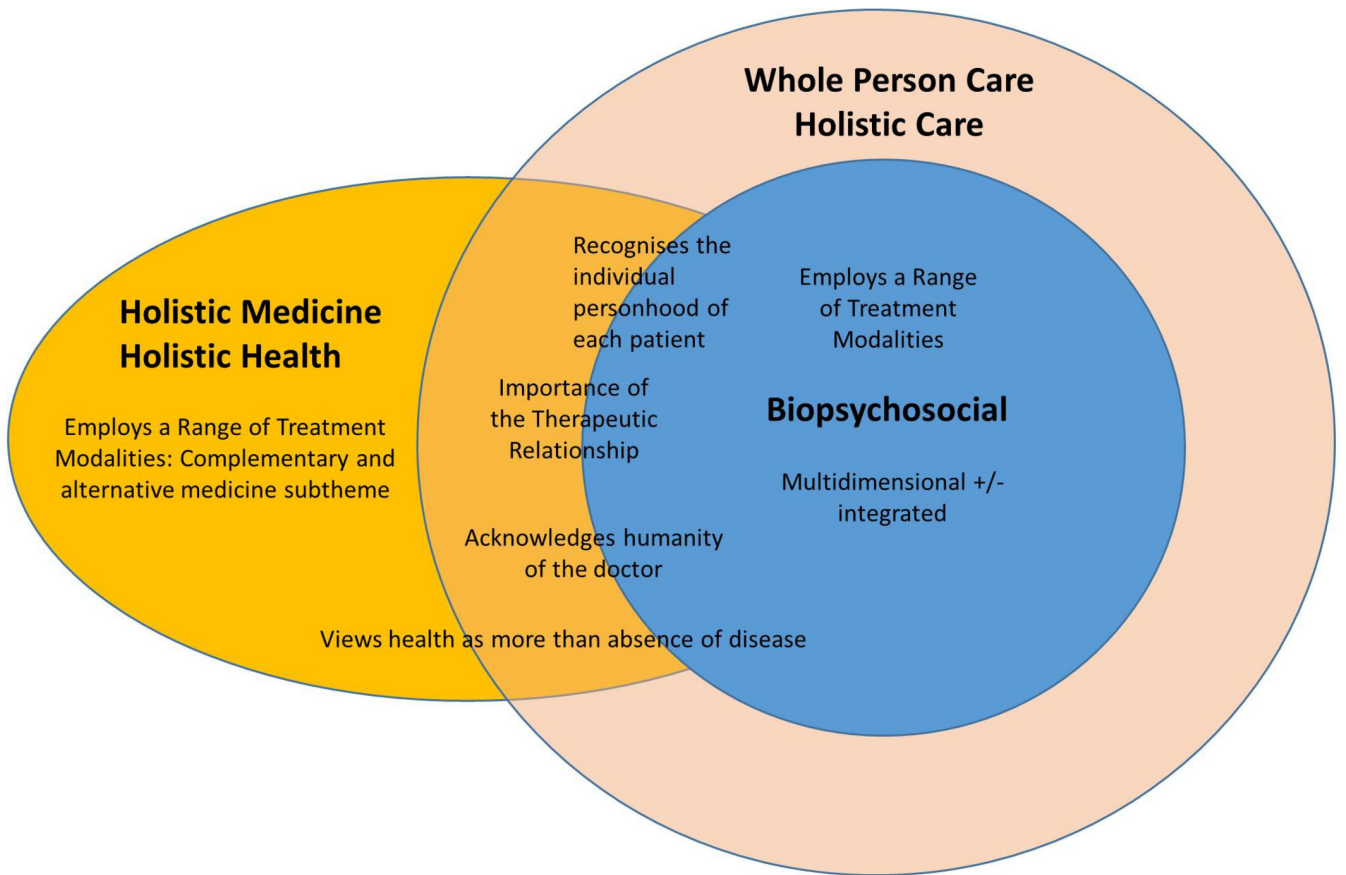

Figure 2 The Inter-relationship between biopsychosocial, whole person and holistic terminology. Features of each approach are included within their respective circles in the diagram. Features placed on the circles' boundaries are a minor feature of the inner circle term, but more pronounced in the outer circle/s term. The diagram illustrates that biopsychosocial was the narrowest but most well defined of the terms, encompassing multidimensionalıintegrated care, and the use of a range of treatment modalities. Minor themes of the biopsychosocial approach include recognising the individual personhood of each patient, and viewing health as more than absence of disease. Some sources that specifically discuss the practical application of the biopsychosocial approach also emphasise the importance of the therapeutic relationship and of acknowledging the humanity of the doctor. Holistic and whole person terminology were broader than biopsychosocial. These terms included a stronger emphasis than biopsychosocial care on the therapeutic relationship, recognition of the patients' individual personhood and the humanity of the doctor, and a view of health as a state of wholeness and balance. Whole person and holistic care were essentially synonymous. 'Holistic medicine'/'holistic health' were related broader terms that sometimes incorporated complementary and alternative medicine.

health. ${ }^{141627293033384345464850}$ van Velden expressed this succinctly, stating that:

[in the] holistic bio-psycho-social model...the doctor-patient relationship changes from one of monologue to one of dialogue, with the doctor no longer instructing the patient but rather involved in negotiating with the latter. People start taking responsibility for personal choices rather than deferring to the rules of institutions. ${ }^{33}$

Illness may be viewed as an opportunity for personal growth. Borins stated that:

sometimes illness can be a creative opportunity for the patient to learn more about himself and the direction he is taking...Sometimes physical or emotional pain can inform a person that he must change his life and grow. ${ }^{14}$

Finally, some sources identified continuity as an important aspect of the doctor-patient relationship. ${ }^{22} 425466$ One author specifically distinguished between holistic and WPC on the basis that continuity was a feature of whole person but not of holistic care. ${ }^{54}$ However, this distinction was not found elsewhere in the literature.
Emphasis on the doctor-patient relationship was prominent within whole person and holistic literature. ${ }^{1416272930323538394245485052545557666769}$ Literature on the biopsychosocial approach was mixed, with the doctor-patient relationship emphasised in papers that specifically focused on the practical application of a biopsychosocial approach. ${ }^{466165}$ An alternative view also existed, that considered the biopsychosocial model an ethically neutral scientific theory rather than an approach to care. ${ }^{41}$

\section{Acknowledges the humanity of the doctor}

The literature placed importance on acknowledgement of the doctor's humanity. This encompasses self-awareness, a 'physician heal thyself' philosophy and the potential for personal growth of the doctor through the clinical interaction. ${ }^{121416293132394244485861656869}$

Several sources argued for the importance of doctors' self-awareness. ${ }^{123250616568}$ Stewart stated that:

holistic care implied a set of values as well as behaviours on the part of the physician; this set would include...awareness of his own person... ${ }^{32}$ 
Epstein also implied the importance of self-reflection when discussing how to apply the biopsychosocial vision, suggesting that doctors ask themselves:

What parts of your self are you engaging in the care of this patient, right now?' and then, 'Does it have to be that way? ${ }^{65}$

A 'physician heal thyself' philosophy was emphasised. ${ }^{141629313942444858}$ Brown stated that:

Holistic care means practitioners matter too. We need to look after ourselves, not only to be an example to our patients, but for our own well-being and that of our families. ${ }^{42}$

\section{Similarly, Borins stated that:}

An important concept of holistic medicine is that of 'Physician, heal thyself'. The more complete we are in our own spiritual, psychological and physical development, the easier it will be to help someone else on the path of positive growth. ${ }^{14}$

A minor subtheme is the potential for personal growth of the doctor through treating the patient. ${ }^{12}{ }^{3969}$ In reference to spiritual care, Anandarajah stated that:

physicians have the potential to heal and be healed through their clinical interactions, as clearly illustrated by numerous physician stories. ${ }^{39}$

Sawa stated that:

The practice of whole-person medicine increases the practitioner's personal growth and develops his or her analytic skill and ability to think in terms of a complex web of contributing factors, rather than in terms of single chains of causal relationships. ${ }^{69}$

Recognising doctors' humanity is a feature of biopsychosocial, holistic and whole person terminology, however the specific subthemes represented in these terminologies differed. Doctors' self-awareness featured in literature describing all three terms. ${ }^{12} 3250616568$ A 'physician heal thyself' philosophy primarily characterised holistic, and to a lesser extent WPC. ${ }^{14} 1629313942444858$ Potential for personal growth of the doctor was a minor theme of some sources on holistic and WPC. ${ }^{12} 3969$

\section{Recognises the individual personhood of each patient}

Recognition of the unique personhood of each patient within their individual context also characterised the literature. ${ }^{284244505560}$ McWhinney stated that:

Understanding and treating illness in its context is what holistic medicine means to me...The natural (holistic) diagnostician tends to notice what is unique in each patient. He is reluctant to classify and label, and he does not separate the disease from the man or the man from his environment. ${ }^{28}$

Focus was placed on the person rather than the disease. ${ }^{1427313338}$ In a study exploring how GPs who practised complementary therapies understood the term 'holism', Adams identified that they viewed:

holism in terms of treating a person rather than simply a patient. These doctors suggest that treating an individual as a patient leads to 'unhealthy' focus upon disease and a failure to acknowledge what they see as the complex and multilayered nature of illness. ${ }^{27}$

Some papers distinguished between disease and illness. ${ }^{22}{ }^{27}$ Strandberg et al's study identified that to have a holistic view:

GPs and nurses have to deal with the gap between 'illness' and 'disease', that is, what the patient experiences and what is the medical problem. ${ }^{22}$

Recognising patients' individual personhood primarily characterised whole person and holistic terminology. ${ }^{22} 272831384042445055$ Variations on this theme were occasionally present in biopsychosocial literature..$^{3360}$

Health as more than absence of disease

Papers incorporating this theme viewed health as more than absence of disease. ${ }^{3340}$ van Velden stated that:

Optimal health is therefore much more than the absence of disease or infirmity. It is the conscious pursuit of the highest qualities of the spiritual, mental, emotional, physical, environmental, occupational and social aspects of the human experience, as illustrated in the bio-psycho-social model. ${ }^{33}$

Some sources conceptualised disease as a state of 'imbalance' and healing as restoring the balance of health. ${ }^{29335369}$ Pietroni, for example, stated that:

Disease or ill-health arises as a result of a state of imbalance, either from within the human being or because of some external force in the environment.... ${ }^{29}$

Preventive health measures were also emphasised. $^{14313235405266}$

Aspects of this theme were included in whole person, holistic and biopsychosocial care. ${ }^{1429} 31-33354052536669$ However, it was most pronounced in the holistic literature. $^{1429} 313240525366$

\section{Employs a range of treatment modalities}

Using a wide range of treatment modalities was the final theme identified. ${ }^{14161827313339485358}$

Examples include Anandarajah's suggestion of treatment modalities in her body, mind, spirit, environment, social, transcendent model of WPC. ${ }^{39}$ These ranged from medication, surgery and physical therapy, to counselling and cognitive therapy, spiritual counselling, compassion, presence and connection. Margalit $e t a l$ s study on the practical application of the biopsychosocial model identified that offering not only medication, but also advice on health promotion and managing emotions characterised a biopsychosocial doctor-patient encounter. ${ }^{46}$ 
A subset of literature using holistic terminology specifically included the use of complementary and alternative medicine (CAM). ${ }^{1827293134404858}$ Pietroni stated that:

An holistic approach...involves a willingness to use a wide range of interventions-traditional medical interventions, alternative approaches and self-help measures. ${ }^{48}$

However, the literature consistently emphasised that CAM is not holistic if used in isolation. ${ }^{14} 161822$ 27-31 3548 Pietroni stated that:

Holism is more than a pot-pourri of therapies. It is an approach to health and disease that transcends any particular therapy...Holism should not be confused with the positive-health movement nor with the complementary medicine movement. Many complementary practitioners do not have an holistic approach and use their therapies in the traditional reductive manner. Conversely, many doctors who know nothing of homeopathy or acupuncture adopt a whole-person approach to their work and have done even before the word holistic became current. ${ }^{30}$

Similarly, in his study on GPs who practise complementary therapies, Adams found that:

Many of the GPs are keen to stress that a holistic approach does not evolve simply with their development of complementary practice. They talk of always having been holistic and how holism is not confined to complementary medicines. ${ }^{27}$

Additionally, McWhinney wrote that:

There is nothing unorthodox about holistic medicine. Unfortunately, the term has been used so much by unorthodox groups of healers, that it is in danger of losing some of its meaning for us. I do not wish to suggest that we should ignore the contribution which unorthodox methods can make to healing. Let us remember, however, that the holistic approach has a long and distinguished history in orthodox medicine itself. $^{28}$

The use of a wide range of treatment modalities characterised whole person, holistic and biopsychosocial care. ${ }^{14} 161827313339485358$ However, the inclusion of CAM was a specific characteristic of holistic terminology. ${ }^{18} 27293134404858$ A distinction was found between various 'holistic' terms in this respect. Sources that discussed 'holistic medicine' or 'holistic health' frequently incorporated CAM, with the exception of McWhinney's paper describing holistic medicine. ${ }^{141627-293158}$ Conversely, sources discussing 'holistic care' rarely referred to the use of CAM. This suggests that the term 'holistic care' does not necessarily imply incorporation of complementary approaches within the GP context. The terms 'holism', 'holistic approach' and 'holistic view' were more varied in this respect, making these terms somewhat more ambiguous. 18272830343638485566
Specific distinctions between whole person, holistic and biopsychosocial terms

Whole person, holistic and biopsychosocial terminology were used interchangeably in several papers. ${ }^{29}{ }^{31-38}$ Some papers did specifically differentiate these terms, but with no consistency among the literature. ${ }^{29} 355455646669$ Davidsen et al implied that the biopsychosocial approach is not holistic due to a lack of integration between the components it addresses. ${ }^{55}$ Grantham differentiated the biopsychosocial approach from holistic medicine, arguing that the latter implied inclusion of CAM. ${ }^{35}$ Howie et al argued that the biopsychosocial approach comprised patient-centeredness in addition to holism. ${ }^{66}$ Sawa differentiated between whole person medicine and biopsychosocial theory by the inclusion of systems theory in the latter. ${ }^{69}$ Wun distinguished between WPC and holistic care by an additional element of continuity of care in the former, stating that:

Whole person care is the accumulation of many incidences of holistic care throughout the lifetime. ${ }^{54}$

Pietroni made a different distinction between these terms, arguing that holistic care includes 'more recent scientific discoveries' (such as psychoneuroimmunology, physics and field forces) in addition to whole person medicine. ${ }^{29}$

On overall analysis of the literature, however, representation of themes discussed above differed between the terms, as illustrated in figure 2.

\section{'Technoscientific holism'}

One alternative description of holism in the literature was 'technoscientific holism' described by Vogt et al. 71 Vogt et al analysed whether P4 systems theory, a 'predictive, preventive, personalised and participatory' approach to medicine, was holistic. In doing so, they specifically differentiated between the 'technoscientific holism' of systems theory, and an approach more similar to that described above which they referred to as the 'holism of humanistic medicine'. ${ }^{70}$ They described 'technoscientific holism' as:

...resulting from an altered, more all-encompassing technological gaze on human life and related changes in biomedicine's methods and philosophy...the whole continuum of health and disease states...is defined as potentially quantifiable, predictable and actionable $^{70}$ (author's emphasis).

This concept is unique in the included literature.

\section{DISCUSSION}

Our analysis suggests that GPs understand WPC to be an approach that considers multiple dimensions of the patient and their context, including biological, psychological, social and possibly spiritual and ecological factors, and addresses these in an integrated fashion that keeps sight of the whole. It employs a range of 
treatment modalities to achieve this aim. Additionally, it emphasises the therapeutic value of the doctor-patient relationship, characterised by an attentive, supportive and collaborative approach. Additional less pervasive features of WPC included recognition of the doctor's humanity (comprising self-awareness and attending to their personal health), and adopting a view of health as more than absence of disease. While few sources drew a distinction between whole person, holistic and biopsychosocial terminology, and several used these terms interchangeably, on overall analysis the terms differed in their emphasis. Their unifying feature was a multidimensional approach to care, in contrast to pure biological reductionism. However, biopsychosocial care was overall described more narrowly than WPC, with clearer definition of the domains of care addressed (biological, psychological, social), while holistic terminology was somewhat broader than WPC, with greater focus on health as wholeness and at times specific inclusion of CAM. The term 'holistic care' was more similar to WPC than 'holistic medicine' or 'holistic health', particularly with respect to the inclusion of CAM in the latter terms. Our findings enable clearer communication through selection of the term most appropriate to the context under discussion.

Our findings were similar to those of previous concept analyses that aimed to define 'holistic' care without a specific focus on general practice, which consisted of mostly nursing-focused literature. ${ }^{20} 2123$ One difference was that these did not specifically emphasise acknowledging the humanity of the practitioner, though they did mention the importance of self-awareness. Our findings are also similar to definitions of whole person or holistic care provided by general practice professional organisations, supporting our reasoning that they are derived from the literature. Several shared an emphasis on a multidimensional approach to care. ${ }^{479}$ Consistent with our findings, their definitions vary in the explicit inclusion of spiritual/existential, cultural and ecological dimensions in a whole person/holistic approach. The Royal College of General Practitioners' definition incorporates an additional focus on the importance of transitioning from a diagnostic/curative to a palliative/supportive role when appropriate. ${ }^{9}$ In view of our findings, organisations with narrower definitions of holistic/WPC may wish to explore whether the GPs they represent consider the additional characteristics identified in our study to be important features of this care, and consider expanding their definitions if this is the case.

There was heterogeneity in included literature, and one theory that may explain this has been suggested by Vanderpool. ${ }^{72}$ He suggested that holistic terminology is used in four distinct ways which have evolved from four approaches to medicine: biopsychosocial, whole person, 'high level healthiness' and 'unconventional and esoteric diagnosis and healing'. His descriptions of biopsychosocial and whole person approaches are similar to those identified in this review, with a greater focus on interpersonal elements in whole person than biopsychosocial care. If his theory is correct, it would explain why 'holistic' is the broadest of the terms studied: it is being used to describe biopsychosocial care, WPC and additional distinct traditions included in other themes we identified (health as a state of wholeness, CAM). The distinction between usages was not as clear in our study as suggested by Vanderpool's framework; however, this may be due to mixing of usages arising from lack of definitional clarity. In view of this and of our findings, Vanderpool's suggestion that terms that are more specific should be used in preference to 'holistic' terminology seems advisable. Where both multidimensional/integrated care and relational elements of care (the doctor-patient relationship, recognising patients' individuality) are in view, we would suggest WPC as the preferred term. If additional themes such as using CAM are in view, we would suggest that this should be stated specifically to avoid confusion. ${ }^{28} 7073$

Our findings raise several practical implications and questions for future research. First, our findings were consistent with previous observations that there is little primary research defining our terms of interest in general practice ${ }^{17}$ Only six pieces of primary research, of variable quality, were identified. ${ }^{22} 2732373846$ Opinion pieces may have reflected the views of GPs with a strong interest in biopsychosocial/whole person/holistic care, and primary research is required to determine the relevance of our findings to the broader GP context. Second, due to heterogeneity among included literature, with many pieces only including a selection of identified themes, it remains unclear whether GPs would share consensus that all of these features characterise the terms of interest, what relative weighting should be applied to each and which aspects of care in addition to biological, psychological and social factors are included. Previous studies have gone some way to addressing this issue, particularly regarding GPs' role in addressing existential and spiritual factors, however work remains to be done. ${ }^{74} 75$ Further research is also required to explore the facilitators, barriers and outcomes of WPC as described. Finally, our definition of WPC shares close similarities with the concepts of 'patient-centred' or 'person-centred' care, and of 'generalism'. ${ }^{76-78}$ We limited our focus in this study to the terms 'whole person', 'holistic' and 'biopsychosocial' care, as these appeared to be used interchangeably in some literature, and frequently differentiated from the term 'patient-centred' or 'person-centred' care. ${ }^{479}$ However, given their close similarities, future studies could explore the relationship between these terms.

Our findings have practical implications in the context of primary health system reforms that aim to provide WPC in response to the increasing prevalence of patients with chronic multimorbidity. They enable GPs to reflect on their individual practice with respect to WPC and could inform focused education and refinement of clinical approaches to provide WPC. They also suggest that WPC requires both multidimensionality and integration. Achieving both can be challenging, particularly where multiple providers are involved in care. However, 
our findings suggest that to provide WPC, this is essential. Proposals for health system redesign have included strategies such as improved communication between providers and integration of healthcare systems which go some way towards addressing this issue. ${ }^{2}$ Our findings suggest that such system changes need to embed an enduring, therapeutic patient-GP relationship which must not be overlooked in a quest to achieve efficiency and tangible outcomes. Previous health reforms have at times neglected this relational aspect of care. ${ }^{11}$ Our findings highlight the danger that such an approach may fail to deliver the whole person approach that ideally characterises primary care. Finally, our work raises ethical questions regarding where the boundaries of the doctors' role lie, and whether employing a multidimensional approach encourages the medicalisation of life. Some authors have argued that this approach in fact breaks the cycle of medicalisation and iatrogenesis through considering non-biomedical contributors to disease. ${ }^{28} 73$ Vogt et al, however, identifies 'the medicalisation of health and life itself' as a potential danger of 'technoscientific holism' which they differentiate from the more 'humanistic holism' discussed in most of the literature, as discussed previously. ${ }^{70} \mathrm{He}$ suggests a focus on 'quaternary prevention' (a concept also discussed by other authors that focusses on preventing overmedicalisation) to address this. ${ }^{80}$ These aspects deserve consideration when applying a whole person approach.

Strengths of this study include its comprehensive search strategy and broad range of literature included, resulting in inclusion of a large number of publications from a broad geographical distribution. As a result, we can be confident that our results represent a comprehensive summary of the understanding of WPC in the English language general practice literature. We do note that most of the countries represented have western-style health systems, though the gatekeeper role of the GP within these systems varies. This may reflect an absence of literature from countries with other health system structures on this topic, or the unavailability of this literature on database searching. Limitations of this study include our decision not to include definitions from professional associations representing general practice, as these are considered to have been derived from existing work rather than introducing original concepts. Our study only included English language literature, so does not provide insight into the usage of similar terminology in other languages. Finally, there is considerable heterogeneity in the papers, and it is possible that other researchers may identify different themes from the same data.

\section{CONCLUSION}

Within general practice literature, the terms whole person, biopsychosocial and holistic care share an emphasis on a multidimensional, integrated approach to care and also incorporate additional themes which vary among the terms as discussed. These findings can inform GPs' self-reflective practice and the design of health systems that foster true WPC. Further research is required to explore the transferability of our findings, together with the facilitators, barriers and outcomes of WPC as defined.

Acknowledgements : We thank Lars Eriksson (librarian, The University of Queensland) for assistance in developing the search strategy.

Contributors $\mathrm{HT}, \mathrm{MB}$ and GM conceived and designed the original protocol. $\mathrm{HT}$ and JR performed the title/abstract screen. HT, MB and GM were involved in screening full-text articles, critical appraisal and data analysis. HT wrote the first draft of the manuscript with MB and GM, and all authors contributed to the subsequent drafts. All authors had full access to all data and HT, MB and GM can take responsibility for the integrity of the data and accuracy of data analysis. GM is the guarantor and affirms that the manuscript is an honest, accurate and transparent account of the study being reported; that no important aspects of the study have been omitted; and that any discrepancies from the study as planned and registered have been explained.

Funding This review is supported by the Royal Australian College of General Practitioners with funding from the Australian Government under the Australian General Practice Training programme.

Competing interests HT's position was funded by the Royal Australian College of General Practitioners with funding from the Australian Government under the Australian General Practice Training programme. MB has received funding from the New South Wales Cancer Institute.

Patient consent Not required.

Provenance and peer review Not commissioned; externally peer reviewed. Data sharing statement № additional data are available.

Open access This is an open access article distributed in accordance with the Creative Commons Attribution Non Commercial (CC BY-NC 4.0) license, which permits others to distribute, remix, adapt, build upon this work non-commercially, and license their derivative works on different terms, provided the original work is properly cited, appropriate credit is given, any changes made indicated, and the use is non-commercial. See: http://creativecommons.org/licenses/by-nc/4.0/.

\section{REFERENCES}

1. American Academy of Family Physicians, American Academy of Pediatrics, American College of Physicians, et al. Joint principles of the patient-centered medical home. 2007. https://www.aafp.org/ dam/AAFP/documents/practice_management/pcmh/initiatives/ PCMHJoint.pdf (accessed 24 Jan 2018).

2. Independent Commission on Whole Person Care. One person, one team, one system: report of the independent commission on whole person care for the labour party. London: Independent Commission on Whole Person Care, 2014.

3. Primary Health Care Advisory Group. Better outcomes for people with chronic and complex health conditions. 2015. https://www. health.gov.au/internet/main/publishing.nsf/Content/76B2BDC12AE5 4540CA257F72001102B9/\$File/Primary-Health-Care-AdvisoryGroup_Final-Report.pdf (accessed 24 Jan 2018).

4. Allen J, Gay B, Crebolder H, et al. The European definition of general practice/family medicine. 2011. http://www.globalfamilydoctor.com/ site/DefaultSite/filesystem/documents/regionDocs/European\% 20Definition\%20of\%20general\%20practice\%203rd\%20ed\%202011. pdf (accessed 24 Jan 2018).

5. Hasegawa H, Reilly D, Mercer SW, et al. Holism in primary care: the views of Scotland's general practitioners. Prim Health Care Res Dev 2005;6:320-8.

6. Reid SJ, Mash R, Downing RV, et al. Perspectives on key principles of generalist medical practice in public service in sub-Saharan Africa: a qualitative study. BMC Fam Pract 2011;12:67.

7. Royal Australian College of General Practitioners. What is general practice? Australia. http://www.racgp.org.au/becomingagp/what-isa-gp/what-is-general-practice/ (accessed 15 Feb 2017).

8. Royal Australian College of General Practitioners. Curriculum for Australian general practice 2016: the five domains of general practice. 2017. http://www.racgp.org.au/Education/Curriculum/Thefive-domains-of-general-practice (accessed 15 Feb 2017).

9. Royal College of General Practitioners. Core capabilities and competences. http://www.rcgp.org.uk/training-exams/gp-curriculum- 
overview/online-curriculum/1-being-a-gp/core-capabilities-andcompetences.aspx (accessed 24 Jan 2018).

10. Wong ST, Watson DE, Young E, et al. What do people think is important about primary healthcare? Healthc Policy 2008;3:89-104.

11. Checkland K, Harrison S, McDonald R, et al. Biomedicine, holism and general medical practice: responses to the 2004 General Practitioner contract. Sociol Health IIIn 2008;30:788-803.

12. Freeman TR, McWhinney IR. Philosophical and scientific foundations of family medicine. McWhinney's textbook of family medicine. USA: Oxford University Press, 2016:104-45.

13. Engel GL. The need for a new medical model: a challenge for biomedicine. Fam Syst Med 1992;10:317-31.

14. Borins M. Holistic medicine in family practice. Can Fam Physician 1984;30:101-6.

15. Hutchinson T, ed. Whole person care: a new paradigm for the 21st century. New York: Springer, 2011.

16. Pietroni P. Holistic medicine: new lessons to be learned. Practitioner 1987;231:1386-90.

17. Van Royen $P$, Beyer $M$, Chevallier $P$, et al. The research agenda for general practice/family medicine and primary health care in Europe. Part 3. Results: person centred care, comprehensive and holistic approach. Eur J Gen Pract 2010;16:113-9.

18. Freeman J. Towards a definition of holism. Br J Gen Pract 2005;55:154-5.

19. Dowrick C, May C, Richardson M, et al. The biopsychosocial model of general practice: rhetoric or reality? Br J Gen Pract 1996;46:105-7.

20. Jasemi M, Valizadeh L, Zamanzadeh V, et al. A Concept analysis of holistic care by hybrid model. Indian J Palliat Care 2017;23:71-80.

21. McEvoy L, Duffy A. Holistic practice-a concept analysis. Nurse Educ Pract 2008:8:412-9.

22. Strandberg EL, Ovhed I, Borgquist L, et al. The perceived meaning of a (w)holistic view among general practitioners and district nurses in Swedish primary care: a qualitative study. BMC Fam Pract 2007;8:8.

23. Ziebarth DJ. Wholistic health care: evolutionary conceptual analysis. $J$ Relig Health 2016;55:1800-23.

24. Kmet L, Lee R, Cook L. Standard quality assessment criteria for evaluating primary research papers from a variety of fields. Canada: Alberta Heritage Foundation for Medical Research, 2004.

25. Joanna Briggs Institute. The Joanna Briggs Institute critical appraisal tools for use in JBI systematic reviews: checklist for text and opinion, 2016.

26. Thomas J, Harden A. Methods for the thematic synthesis of qualitative research in systematic reviews. BMC Med Res Methodol 2008;8:45.

27. Adams J. Enhancing Holism? GPs' explanations of their complementary practice. Complement Health Pract Rev 2001;6:193-204.

28. McWhinney IR. The meaning of holistic medicine. Can Fam Physician 1980;26:1096-7.

29. Pietroni P. Holistic medicine - new map, old territory. The British Journal of Holistic Medicine 1984;1:3-13.

30. Pietroni P. Holism, complementary therapy and primary care. Holistic Medicine 1986;1:91.

31. Pietroni P. Is complementary medicine holistic? Complement Ther Nurs Midwifery 1997;3:9-11

32. Stewart MA. A study of the holistic approach in primary care. Canada: The University of Western Ontario, 1975.

33. van Velden DP. The bio-psycho-social approach to health and disease. SADJ 2003;58:191-6.

34. Ben-Arye E, Steinmetz D, Ezzo J. Two women and cancer: the need for addressing spiritual well-being in cancer care. Spiritual Clin Pract 2013;1:71-7.

35. Grantham P. Behavioral medicine and university departments of family practice. Can Fam Physician 1983;29:2336-8.

36. Jimenez V. Combining the biologic with the psychosocial. Why family physicians conducting research should be interested. Can Fam Physician 2004;50:169-70.

37. Murray SA, Kendall M, Boyd K, et al. General practitioners and their possible role in providing spiritual care: a qualitative study. $\mathrm{Br} J \mathrm{Gen}$ Pract 2003;53:957-9.

38. O'Brien R, Wyke S, Guthrie B, et al. An 'endless struggle': a qualitative study of general practitioners' and practice nurses' experiences of managing multimorbidity in socio-economically deprived areas of Scotland. Chronic IIIn 2011;7:45-59.

39. Anandarajah $\mathrm{G}$. The $3 \mathrm{H}$ and BMSEST models for spirituality in multicultural whole-person medicine. Ann Fam Med 2008;6:448-58.

40. Borins M. What is health? An apple a day - a holistic health primer. Ontario: Wholistic Press, 1980:11-14.

41. Brody $\mathrm{H}$. The biopsychosocial model, patient-centered care, and culturally sensitive practice. J Fam Pract 1999;48:585-7.
42. Brown CK. Practicing medicine as if people do matter. Complement Ther Clin Pract 2007:13:215-6.

43. Doherty WJ, Baird MA, Becker LA. Family medicine and the biopsychological model: the road toward integration. Marriage Fam Rev 1987;10:51-69.

44. Ellyson CD. A general practitioner evaluates the problem of treating the whole patient. J lowa State Med Soc 1958;48:487-9.

45. Fortin M, Hudon C, Bayliss EA, et al. Caring for body and soul: the importance of recognizing and managing psychological distress in persons with multimorbidity. Int J Psychiatry Med 2007;37:1-9.

46. Margalit AP, Glick SM, Benbassat J, et al. A practical assessment of physician biopsychosocial performance. Med Teach 2007;29:e219-e226.

47. Medalie JH. Dimensions of family medicine and practice. In: Medalie $\mathrm{JH}$, ed. Family medicine - principles and applications. Baltimore, USA: The Williams and Wilkins Company, 1978:3-20.

48. Pietroni PC. Alternative medicine. Practitioner 1986;230:1053-4.

49. Rabinowitz PM. Psychosocial aspects of primary care: theoretical models of practice. In: Feinstein RE, Brewer AA, eds. Primary care psychiatry and behavioral medicine: Brief office treatment and management pathways. New York: Springer Publishing Co, 1999:1-13.

50. Risdon C, Edey L. Human doctoring: bringing authenticity to our care. Acad Med 1999;74:896-9.

51. Sheldon MG. The Christian approach to whole-person medicine. J $R$ Coll Gen Pract 1989;39:166.

52. Stange KC. A science of connectedness. Ann Fam Med 2009;7:387-95.

53. Sturmberg J. How to teach holistic care-meeting the challenge of complexity in clinical practice. Educ Health 2005;18:236-45.

54. Wun YT. "What is general/family practice?" Let us define it. The Hong Kong Practitioner 2002;24:498-502.

55. Davidsen AS, Guassora AD, Reventlow S. Understanding the bodymind in primary care. Med Health Care Philos 2016;19:581-94.

56. DeGruy FV, Etz RS. Attending to the whole person in the patientcentered medical home: the case for incorporating mental healthcare, substance abuse care, and health behavior change. Fam Syst Health 2010;28:298-307.

57. Fraser-Darling A. A Christian dimension to holistic care in family practice. Journal of Psychology and Christianity 1985;4:95-7.

58. Pietroni P. Holistic medicine. J R Coll Gen Pract 1984;34:463-4.

59. Rosenblatt RA. Family medicine in four dimensions: developing an ecobiopsychosocial perspective. Fam Med 1997;29:50-3.

60. Hepworth J, Cushman RA. "Biopsychosocial" - essential but not sufficient. Fam Syst Health 2005;23:406-9.

61. Epstein RM, Borrell-Carrio F. The biopsychosocial model: Exploring six impossible things. Fam Syst Health 2005;23:426-31.

62. Herman J. The need for a transitional model: a challenge for biopsychosocial medicine? Fam Syst Health 1989:7:106-11.

63. Pauli HG, White KL, McWhinney IR. Medical education, research, and scientific thinking in the 21st century (part two of three). Educ Health 2000;13:165-72.

64. Rabinowitz PM, Cullen MR, Feinstein RE. Host/environment medicine: a family practice model for the future. Fam Med 1998;30:297-300.

65. Epstein RM. Realizing Engel's biopsychosocial vision: resilience, compassion, and quality of care. Int J Psychiatry Med 2014;47:275-87

66. Howie JG, Heaney D, Maxwell M. Quality, core values and the general practice consultation: issues of definition, measurement and delivery. Fam Pract 2004;21:458-68.

67. McWhinney IR. The importance of being different: part 2: transcending the mind-body fault line. Can Fam Physician 1997;43:404-6.

68. Medalie JH. Angina pectoris: a validation of the biopsychosocial model. J Fam Pract 1990;30:273-80.

69. Sawa RJ. Incorporating the family into medical care. Can Fam Physician 1988;34:87-93.

70. Vogt H, Hofmann B, Getz L. The new holism: P4 systems medicine and the medicalization of health and life itself. Med Health Care Philos 2016;19:307-23.

71. Vogt $\mathrm{H}$, Ulvestad E, Eriksen TE, et al. Getting personal: can systems medicine integrate scientific and humanistic conceptions of the patient? J Eval Clin Pract 2014;20:942-52.

72. Vanderpool HY. The holistic hodgepodge: a critical analysis of holistic medicine and health in America today. J Fam Pract 1984;19:773-81.

73. Borrell-Carrió F, Suchman AL, Epstein RM. The biopsychosocial model 25 years later: principles, practice, and scientific inquiry. Ann Fam Med 2004;2:576-82.

74. Assing Hvidt E, Søndergaard J, Ammentorp J, et al. The existential dimension in general practice: identifying understandings and 
experiences of general practitioners in Denmark. Scand $J$ Prim Health Care 2016;34:387-93.

75. Vermandere M, De Lepeleire J, Smeets L, et al. Spirituality in general practice: a qualitative evidence synthesis. Br J Gen Pract 2011;61:e749-e760.

76. Howe A. What's special about medical generalism? The RCGP's response to the independent Commission on Generalism. Br J Gen Pract 2012;62:342-3.

77. Stange KC. The generalist approach. Ann Fam Med 2009;7:198-203.
78. Stewart M, Brown JB, Weston WW, et al. Patient-centered medicine: transforming the clinical method. 2nd edn. UK: Radcliffe Medical Press Limited, 2003.

79. Royal College of General Practitioners. Curriculum for speciality training for general practice: the core statement: being a general practitioner. London: Royal College of General Practitioners, 2007.

80. Jamoulle M. Quaternary prevention, an answer of family doctors to overmedicalization. Int J Health Policy Manag 2015;4:61-4. 